\title{
EVALUATION OF THE ESTIMATION OF DIFFUSE IRRADIANCE FROM GLOBAL AND DIRECT NORMAL IRRADIANCE MEASUREMENTS
}

\author{
C. BRUCE BAKER \\ 2450 Hayward, Research Activities Building, Department of Atmospheric Science, The University of \\ Michigan, Ann Arbor, MI 48109, U.S.A.
}

(Received 1 May 1982; accepted 9 November 1982)

\begin{abstract}
As part of a radiometer intercomparison experiment, different combinations of pyranometer and pyrheliometers were used to estimate diffuse solar irradiance on a horizontal surface. Sixteen combinations were possible with four pyranometers and four pyrheliometers. The values were intercompared and then compared to the measured values, obtained with a solar tracking/occulting disc system. The difference in estimated values using different radiometer combinations varied from 1 to $21 \mathrm{~W} / \mathrm{m}^{2}$. It was found that uncertainty in measuring the global irradiance accounted for most of the difference in estimated values. In the worst case, a 2.1 per cent difference in the global irradiance as measured by two different pyranometers caused a 12 per cent difference in estimates of the diffuse irradiance. It is shown that, if the estimated and measured values are analyzed statistically, agreement to within 1 per cent is possible.
\end{abstract}

\section{INTRODUCTION}

The diffuse (scattered) component of solar radiation, in spite of its small magnitude compared to the direct normal component, plays an active role in thermal, chemical and biological processes at the earth's surface. It can comprise as much as $40 \%$ of the global radiation for a high turbidity or large zenith angle and cloudless sky condition [1].

Three methods are commonly used to determine the diffuse component: in one method a shadow band shades the sun, in the second an occulting disc is used with a solar tracker, and in the third a pyrheliometer and pyranometer are used to determine diffuse radiation indirectly by means of the following relationship:

$$
d e=G-D \cos (z)
$$

where $G$ is the global solar irradiance on a horizontal surface, $D$ the direct normal solar irradiance, $z$ the solar zenith angle, and de the (estimated) diffuse solar irradiance on a horizontal surface.

In the present paper, values of diffuse irradiance calculated with eqn (1) are compared with measured values $(\mathrm{dm})$. The measurements were made during a radiometer comparison experiment held in Burlington, Vermont, 17-18 June 1981. The participants in the experiment were personnel from the Solar Energy Research Institute (SERI), State University of New York at Albany (SUNY), Burlington National Weather Service Office, Hollis Observatory, and University of Michigan (UM). The measurements made for the comparison of $d e$ to $d m$ involved four Eppley precision spectral pyranometers (PSP) for global irradiance, three Eppley normal incidence pyrheliometers and a TMI active cavity radiometer (ACR) for direct normal irradiance, and an Eppley PSP with a solar tracking/occulting disc system for diffuse irradiance (Fig. 1).

\section{MEASUREMENTS AND DATA HANDLING}

Radiometer output voltages (except for the ACR) were recorded every $30 \mathrm{sec}$ on Fluke 10-channel data logger with $1 \mu \mathrm{V}$ sensitivity and $200 \mathrm{mV}$ range. The ACR voltages were read from a Guildline digital voltmeter and were entered manually onto the data log. gers' printed paper tape. Data were obtained for about $1 \frac{1}{2} \mathrm{hr}$ on 17 June during a scattered to broken cloud condition between 1000 and 1200 EST which corresponded to a solar zenith angle range of 30.4-21.0 On 18 June, data were obtained for $2 \frac{1}{2} \mathrm{hr}$ with a cloudless sky from 0800 to $1030 \mathrm{EST}$, with solar zenith angles between 51.5 and $27.2^{\circ}$. During both measurement periods, solar alignments of the diffuse tracking disc and pyrheliometers were closely monitored. The raw data were entered onto magnetic type by UM and forwarded to SERI for validation. Irradiance values were calculated from the corrected raw data and calibration factors supplied by the respective participants[2].

\section{ESTIMATE OF DIFFUSE IRRADIANCE}

The variation in calculated diffuse radiation for the various instrument combinations was determined by first averaging the irradiance for each observation as follows:

$$
\begin{gathered}
\bar{G}_{i}=\sum_{j=1}^{4} G_{i j} / 4 \quad i=1, \ldots, N \\
\bar{D}_{i}=\sum_{k=1}^{4} D_{i k} / 4 \quad i=1, \ldots, N
\end{gathered}
$$

where $\bar{G}_{i}$ is the average global irradiance value for the 


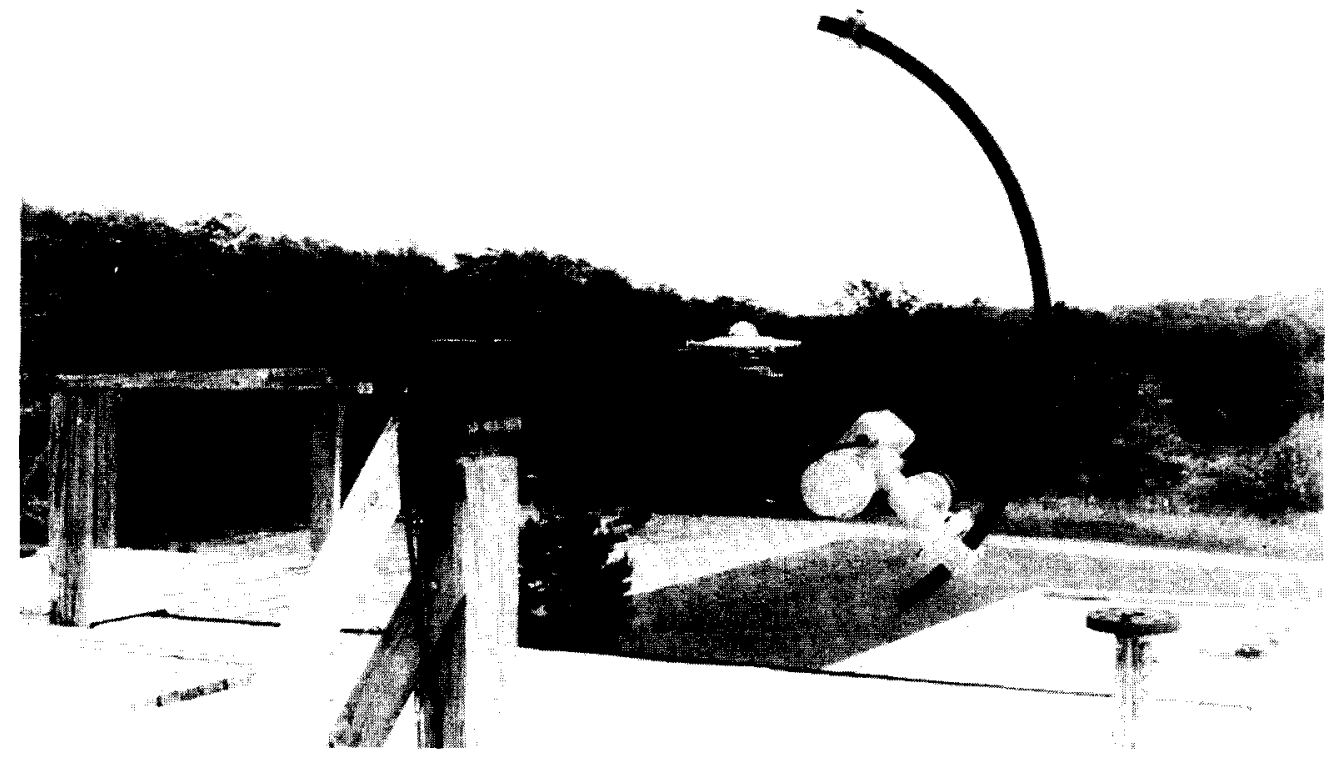

Fig. 1. Eppley occulting disc tracker unit with PSP.

$i$ th observation, $G_{i j}$ is the value in $\mathrm{W} / \mathrm{m}^{2}$ for the $i$ th observation and $j$ th pyranometer, $\bar{D}_{i}$ is the average direct irradiance value for the $i$ th observation and $D_{i k}$ is the value in $\mathrm{W} / \mathrm{m}^{2}$ of the direct irradiance for the $i$ th observation and $k$ th pyrheliometer. It is assumed that the most representative estimates of global and direct irradiances for each observation are the average values $\bar{G}_{i}$ and $\bar{D}_{i}$, respectively. In this way, one instrument does not carry the burden of being a reference unit. The interdependency between the test instrument $*$ and reference instrument and possible errors due to varying responses to the angle of incidence of radiation are minimized. This procedure was suggested by the SERI personnel.

The combination of instruments ( 4 pyranometers and 4 pyrheliometers) allowed the diffuse radiation to be computed in 16 different ways. Figures 2 and 3 show the average value of the estimated diffuse component for each day and each instrument combination, where:

$$
\overline{d e}_{j k}=\sum_{i=1}^{N} d e_{i j k} / N
$$

$\overline{d e}_{j k}$ is the average estimate of the diffuse irradiance for the $j$ th pyranometer and $k$ th pyrheliometer, $d e_{i j k}$ is the estimate of the diffuse irradiance for the $i$ th observation, $j$ th pyranometer and $k$ th pyrheliometer and $N$ is the number of observations. Each of the four sections for each day corresponds to one pyrheliometer and four pyranometers. The recurring variation within each section illustrates the effect of each pyranometer on the estimate of the diffuse irradiance.

\section{ERROR ANALYSIS}

The data were examined as a function of time to determine the sensitivity of eqn (1) to an error in an instrument reading. A correction factor for each instrument was calculated by:

$$
\begin{aligned}
C G_{j} & =\sum_{i=1}^{N} \frac{\bar{G}_{i}}{G_{i j}} / N \quad j=1, \ldots, 4 \\
C D_{k} & =\sum_{i=1}^{N} \frac{\bar{D}_{i}}{D_{i k}} / N \quad k=1, \ldots, 4 .
\end{aligned}
$$

The error in $\mathrm{W} / \mathrm{m}^{2}$ for each instrument was then determined from:

$$
\begin{gathered}
E_{j}=\sum_{i=1}^{N}\left(1-C G_{j}\right) G_{i j} / N \quad j=1, \ldots, 4 \\
E_{k}=\sum_{i=1}^{N}\left(1-C D_{k}\right) D_{i k} / N \quad k=1, \ldots, 4
\end{gathered}
$$

$E_{j}$ is the average error for the $j$ th pyranometer and $E_{k}$ the error for the $k$ th pyrheliometer. The error propagation in eqn (1) due to an error in the measurement of the global or direct irradiances may be expressed by:

$$
W_{j k}=\left[\left(E_{j}\right)^{2}+\left(E_{k} \cos (z)\right)^{2}\right]^{1 / 2}
$$

where $W_{j k}$ is the uncertainty in $\mathrm{W} / \mathrm{m}^{2}$ of $d e_{j k}$, the estimated diffuse component for the $j$ th pyranometer and $k$ th pyrheliometer combination.

The difference found in $\overline{d e}_{j k}$ between different instru- 
17 JUNE 1981

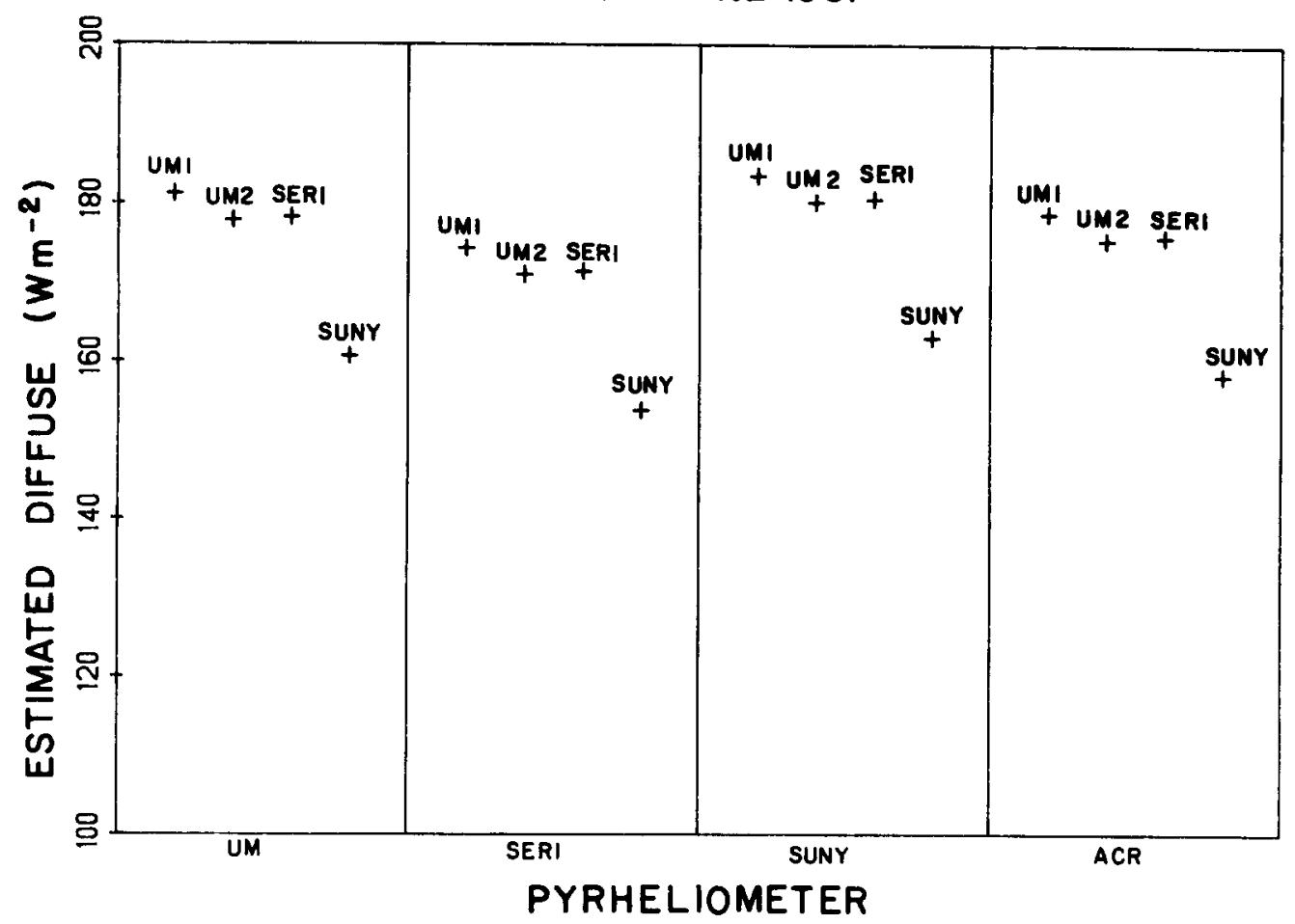

Fig. 2. Estimate of the diffuse irradiance for a given pyrheliometer and all four pyranometers for 17 June 1981.

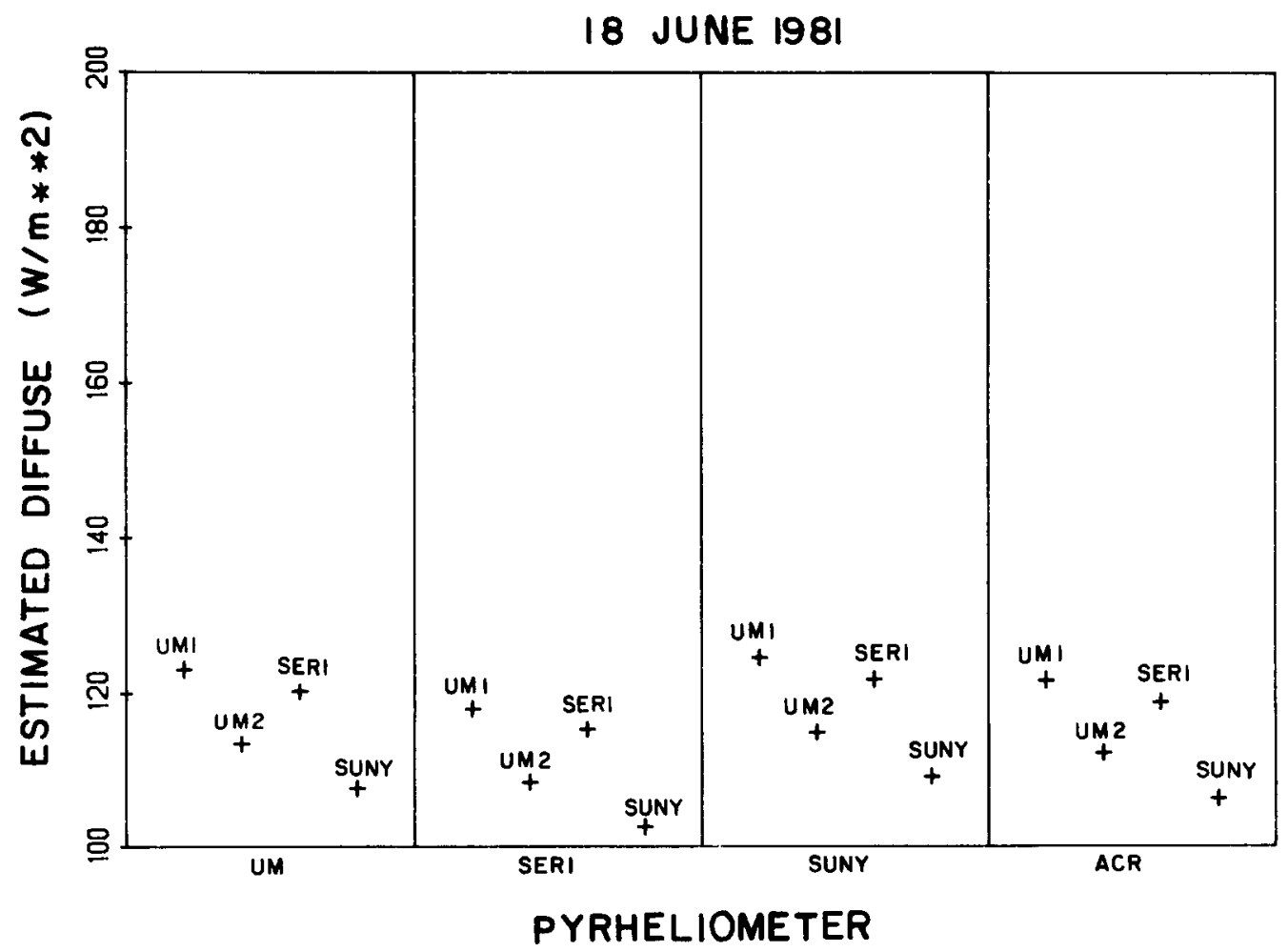

Fig. 3. Same as Fig. 2 except for 18 June 1981. 
ment combinations agrees with the difference in $W_{j k}$ for the same pairs of instruments. For example, the maximum differences observed in $\overline{d e}_{j k}$ occurs between the UM1 and SUNY pyranometers, being $20.5 \mathrm{~W} / \mathrm{m}^{2}$ on day 1 and $17.5 \mathrm{~W} / \mathrm{m}^{2}$ on day 2 . The difference in $W_{j k}$ for the same two pyranometers and pyrheliometer were $20.1 \mathrm{~W} / \mathrm{m}^{2}$ and $17.6 \mathrm{~W} / \mathrm{m}^{2}$ respectively. In all cases except one, both the recurring variation within a section and the magnitude of the difference in $\overline{d e}_{j k}$ as determined by two different pyranometers and one pyrheliometer agree with $W_{j k}$ to within $1 \mathrm{~W} / \mathrm{m}^{2}$. In the anomalous case, the UM2 pyranometer behaved quite erratically on both days causing the standard deviation in $C G_{j}$ to be twice that of the other pyranometers. An interesting point that illustrates the sensitivity of eqn (1) to the measured global irradiance is that the UMI and SUNY pyranometers differ by only 2.1 per cent in their estimate of the global irradiance as compared to $\bar{G}_{i}$ yet if data for the same pyrheliometer are used to calculate eqn (1), the diffuse radiation differs by 12 per cent. Similar comparisons of the effect different pyrheliometers have on $\overline{d e}_{j k}$ can also be made but in eqn (9), $\left(E_{j}\right)^{2}$ is an order of magnitude greater than $\left(E_{k} \cos (z)\right)^{2}$ thus indicating that the errors in the pyranometer measurements dominate.

It should be emphasized that these results apply to the Burlington data where alignments of the pyrheliometer were carefully maintained. The error in the measurement of direct radiation as a function of misalignment ranges from 0.5 per cent for an angular radius of 1.2 from the center of the diopter target to 20 per cent at a radius of $2.3^{\circ}[3] . E_{k} \cos (z)$ approaches the magnitude of $E_{j}$ when the error in $E_{k}$ approaches 10 per cent.

Thus the misalignment of the pyrheliometers can be a significant source of error in eqn (1), but in this study the uncertainty in the pyranometer's performance characteristics is the major source of error. Figures 2 and 3 show that the diffuse irradiance calculated independently with four different pyranometers and the same pyrheliometer yield large differences in estimating the diffuse component. These differences are explained by the uncertainty in the estimates of the global and direct irradiances from the respective instruments.

\section{COMPARISON OF ESTIMATED TO MEASURED DIFFUSE IRRADIANCE}

To determine how well the estimated diffuse irradiance compares to the diffuse irradiance as measured with the occulting disc tracker unit, the irradiance values for each instrument were first corrected by $C D_{k}$ or $C G_{j}$, as required, and a new $C \overline{d e}_{j k}$ was calculated for each instrument combination as follows:

$$
C \overline{d e}_{j k}=\sum_{i=1}^{N}\left[\frac{G_{i j}}{C G_{j}}-\frac{D_{i k}}{C D_{k}} \cos \left(z_{i}\right)\right] / N
$$

$C \overline{d e}_{j k}$ is the corrected value for the average estimate of diffuse irradiance for the $j$ th pyranometer and $k$ th pyrheliometer. The average values of the ratio of the corrected estimated diffuse irradiance to the measured diffuse irradiance $\left(C \overline{d e}_{j k} / d m\right)$ were computed as follows:

$$
\bar{R}_{j k}=\sum_{i=1}^{N} \frac{d e_{i j k}}{d m_{i}} / N
$$

Figures 4 and 5 show the values of $\bar{R}_{j k}$ for the 16 pyrheliometer-pyranometer combinations for each day. With correction factors applied to the respective instrument irradiance values, there is much more uniformity within sections. It is quite evident, however, that $\overline{C d e}_{j k}$ underestimates the measured diffuse irradiance by as much as 15 per cent. How well $C \overline{d e}_{j k}$ approximates the diffuse irradiance is a strong function of the magnitude of the measured diffuse component. For example on Day 1, $315 \mathrm{~W} / \mathrm{m}^{2} \geq d m \geq 136 \mathrm{~W} / \mathrm{m}^{2}$ and $0.97 \geq \bar{R}_{j k} \geq 0.93$ and on Day $2,163 \mathrm{~W} / \mathrm{m}^{2} \geq d m \geq 111 \mathrm{~W} / \mathrm{m}^{2}$ and $0.88 \geq \bar{R}_{j k} \geq 0.85$.

It is likely that the support used for the occulting disc tracker unit contributed to the apparent underestimation of the corrected estimated diffuse irradiance. A wooden 4" $=4$ " support about $0.12 \mathrm{~m}$ to the north side of the tracker unit projected $0.1 \mathrm{~m}$ above the PSP thermopile plane. Radiation reflected from this surface onto the thermopile would cause the measured diffuse irradiance to be greater than it should be. An estimate of the additional radiation impinging on the sensor due to the reflection of direct and scattered radiation was made with an anisotropic all-sky expression [4]:

$$
\begin{aligned}
I_{T}=\bar{D}_{i} \sin \left(z_{i}\right)+d m_{i} & \left(\frac{1+\cos \epsilon}{2}\right)\left(1+F \sin ^{3} \epsilon / 2\right) \\
& \times\left(1+F \cos ^{2} \psi \sin ^{3}(90-\alpha)\right)
\end{aligned}
$$

where $I_{T}$ is the total radiation impinging on the vertical post, $\epsilon$ the angle above the horizontal, $\alpha$ the solar elevation angle, $F=1-\left(d m_{i} / \bar{G}_{i}\right)^{2}$ and $\cos \psi=\sin (\phi-\epsilon) \sin \delta+\cos (\phi-\epsilon) \cos \delta \cos h$ where $\phi$ is the station latitude, $\delta$ the declination angle of the sun and $h$ the hour of the sun. No ground reflection term is considered in this expression. The total radiation $I_{T}$ was calculated for each observation and was assumed to be reflected isotropically over $2 \pi$ steradians. The albedo of the post was assumed to be 0.30 and the portion of scattered sky radiation blocked to the north by the post was assumed negligible. The value obtained was subtracted from $d m_{i}$ and a new ratio calculated, which led to $1.02 \geq \bar{R}_{j k} \geq 0.98$ on Day 1 and $0.96 \geq \bar{R}_{j k} \geq 0.91$ on Day 2 . The reflected radiation factor decreased $d m$ by approximately $10 \mathrm{~W} / \mathrm{m}^{2}$ which appeared in $\bar{R}_{j k}$ as a 5-8 per cent increase. It is still evident that the best estimate of the diffuse irradiance using eqn (1) decreses in accuracy as the scattered radiation field decreases in magnitude. In the Burlington data $C \overline{d e}_{j k}$ 




Fig. 4. Ratio of corrected estimated diffuse irradiance to the measured diffuse irradiance for 17 June 1981 .

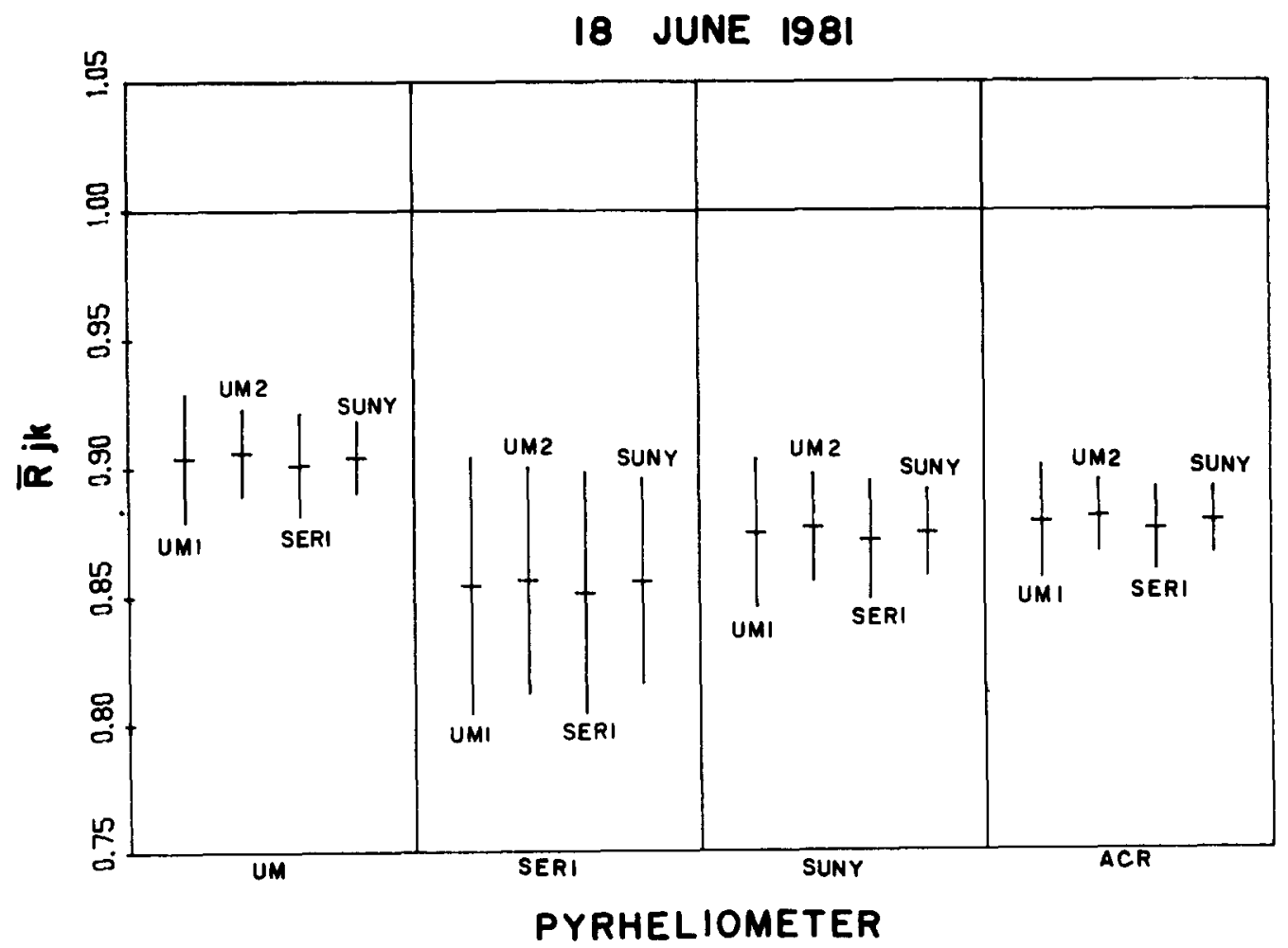

Fig. 5. Same as Fig. 4 except for 18 June 1981. 
was 9 per cent low in the worst case. To explain the remaining discrepancy a least squares linear regression was performed on the data. An average $d e_{i}$ was found for each observation where:

$$
\overline{d e}_{i}=\sum_{k=1}^{4} \sum_{j=1}^{4} \frac{C d e_{i j k}}{16} .
$$

This was considered the best estimate of de. A best-fit line was determined for the data shown in Fig. 6, where $\overline{d e}_{i}$ is on the abscissa and $d m_{i}$ on the ordinate. The expression:

$$
d e=11.45+0.9444 \overline{d e}_{i}
$$

approximated the measured diffuse irradiance, $d m$, to within 1 per cent for any given time.

Thus to obtain an accurate representation of the diffuse irradiance with the indirect method, a comparison should be made between the pyranometer and pyrheliometer used for eqn (1) and the measured diffuse using an occulting disc tracker unit. As the diffuse irradiance decreases the more important the comparison becomes. In the case of the Burlington data the regression serves to account for the surface reflectance term ignored in eqn (12) and the subjective alignment of the occulting disc tracker unit.

\section{CONCLUSION}

This study shows an important consideration necessary to estimate the diffuse irradiance indirectly. A statistical analysis of the estimated diffuse versus measured diffuse is necessary to obtain reliable data from the indirect method of estimating the diffuse component. The major reason is because a small error in the global component can lead to a large error in the estimated diffuse irradiance. In the Burlington data a 2 per cent difference in the estimate of the global irradiance led to a 12 per cent error in the estimate of the diffuse irradiance.

The greater the uncertainty in the measured global and direct irradiances the greater the need for a statistical analysis to account for these discrepancies. A linear regression accounted for the uncertainties in the Burlington data but the misalignment problem was minimized since the pyrheliometers and occulting disc tracker were continuously monitored. The misalignment of the occulting disc tracker and/or pyrheliometer can cause a significant problem. There is no method at present that will assure that the occulting disc is blocking the same portion of the celestial dome as that viewed by the pyrheliometer. The pyrheliometers have a diopter-target alignment mechanism whereas the occulting disc/tracker unit does not, thus making it necessary to be subjectively aligned. An alignment mechanism similar to that for the pyrheliometers, and/or a single tracker mechanism that could drive the occulting disc tracker and pyrheliometer simultaneously, should be designed so that the error can be quantified and minimized.

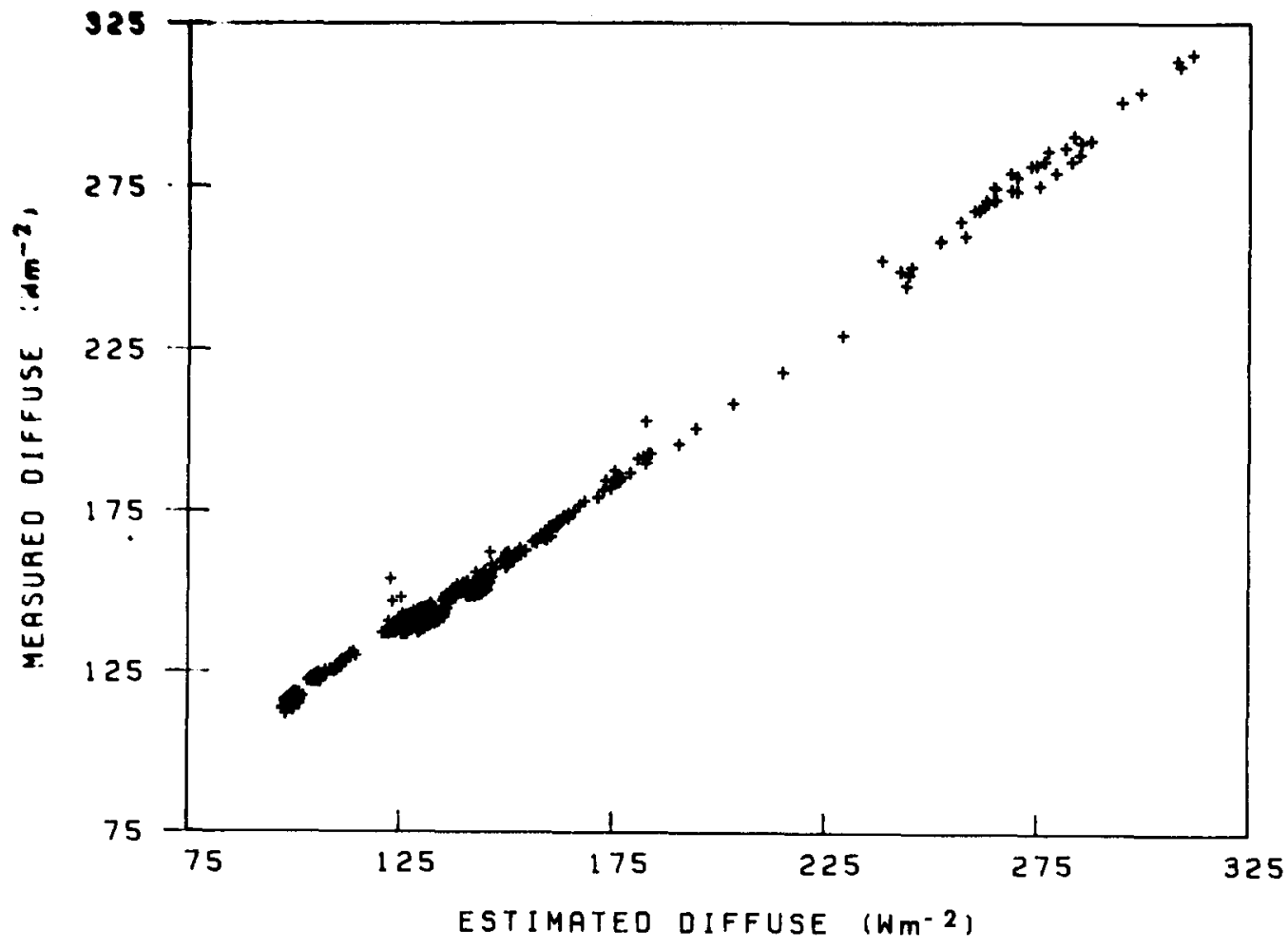

Fig. 6. Diffuse radiation as measured with Eppley occulting-disc tracker vs the average value of the estimate of diffuse using all 16 instrument combination values. 
Acknowledgements -I would like to thank Lester Machta and Monte Poindexter of the National Oceanic and Atmospheric Administration for providing funding support, $\mathrm{Mi}$ chael R. Weber for the computer graphics and text/review; and Kay Cease for typing the manuscript.

\section{REFERENCES}

1. H. A. McCartney, Spectral distribution of solar radiation, II: global and diffuse: $Q$. J. Roy. Meteor. Soc. 104, 911-926 (1978).
2. D. R. Myers, Results of a Training Exercise in the Comparison and Calibration of Pyranometers and Pyrheliometers. Solar Energy Research Institute, Golden, Colorado SERI/TR-215-1519 (1982).

3. G. Clark, J. E. Rudzki, Jr., F. M. Loxsom and R. A. Bartels, Workshop of Solar Radiation Data. Trinity University, San Antonio, Texas (1980).

4. T. M. Klucher, Evaluation of models to predict insolation on tilted surfaces. Solar Energy 23, 111-114 (1979) 